\title{
Moraxella nonliquefaciens bloodstream infection and sepsis in a pediatric cancer patient: case report and literature review
}

\author{
Carlos L. Correa-Martínez ${ }^{1 *}$ (D), Kerstin K. Rauwolf ${ }^{2}$, Franziska Schuler ${ }^{3}$, Miriam Füller ${ }^{2}$, Stefanie Kampmeier ${ }^{1}$ and \\ Andreas H. Groll ${ }^{2 *}$
}

\begin{abstract}
Background: Moraxella nonliquefaciens is a usually non-pathogenic biofilm-producing Gram-negative coccobacillus which may colonize the upper respiratory tract, rarely causing invasive disease. Although very rare, bloodstream infections caused by this organism have been described, showing often a fatal outcome. Here, we report the case of a pediatric cancer patient with bloodstream infection and sepsis due to M. nonliquefaciens showing full recovery after appropriate antibiotic treatment.

Case presentation: A three-year-old boy with stage IV neuroblastoma was admitted for high-dose chemotherapy with autologous stem cell rescue after standard neuroblastoma treatment. Despite receiving antimicrobial prophylaxis with trimethoprim/sulfamethoxazole, acyclovir and amphothericin B, the patient presented with fever of up to $39.5^{\circ} \mathrm{C}$ and neutropenia. Besides a chemotherapy-related mucositis and an indwelling Broviac catheter (removed), no infection focus was identified on physical examination. Moraxella nonliquafaciens was identified in blood cultures. After antibiotic treatment and neutrophil recovery, the patient was fit for discharge.

Conclusions: The case described highlights the importance of an otherwise non-pathogenic microorganism, especially in immunosupressed cancer patients. It should be kept in mind that, although very infrequently, Moraxella nonliquefaciens may cause bloodstream infections that can be successfully treated with prompt focus identification and antibiotic therapy.
\end{abstract}

Keywords: Sepsis, Moraxella nonliquefaciens, Children, Infection, Cancer

\section{Background}

Moraxella nonliquefaciens is a Gram-negative coccobacillus that may be found in the upper respiratory tract as part of the local flora [1], rarely causing disease. Cases of localized infection have been described, including meningitis [2], endophthalmitis [3, 4], endocarditis [5-7] and pneumonitis [8]. To the best of our knowledge, only four cases of bloodstream infection with this pathogen have been reported to date (Table 1) [9-12], only two of them

\footnotetext{
*Correspondence: carlos.correa@ukmuenster.de:

andreas.groll@ukmuenster.de

${ }^{1}$ Institute of Hygiene, University Hospital Münster, Robert-Koch-Strasse 41 , 48149 Münster, Germany

${ }^{2}$ Department of Pediatric Hematology and Oncology and Center for Bone Marrow Transplantation, University Children's Hospital Münster, Münster, Federal Republic of Germany

Full list of author information is available at the end of the article
}

in hemato-oncological patients $[9,10]$ who subsequently died. Here, we present the first case of bloodstream infection and sepsis by $M$. nonliquefaciens in a neutropenic pediatric cancer patient showing full recovery following central venous catheter removal and appropriate antibiotic treatment.

\section{Case presentation}

We present the case of a three-year-old boy with stage IV neuroblastoma admitted for high-dose chemotherapy with treosulfan $\left(12 \mathrm{~g} / \mathrm{m}^{2} \times 3\right.$ days $)$ and melphalan $\left(140 \mathrm{mg} / \mathrm{m}^{2} \times\right.$ 1 day) with autologous stem cell rescue for consolidation after multimodal treatment consisting of intensive chemotherapy, surgery, and $\mathrm{I}^{131}$-metaiodobenzylguanidine therapy according the recommendations of the German Neuroblastoma Registry 2016 [13]. Antimicrobial prophylaxis

C) The Author(s). 2019 Open Access This article is distributed under the terms of the Creative Commons Attribution 4.0 International License (http://creativecommons.org/licenses/by/4.0/), which permits unrestricted use, distribution, and reproduction in any medium, provided you give appropriate credit to the original author(s) and the source, provide a link to the Creative Commons license, and indicate if changes were made. The Creative Commons Public Domain Dedication waiver (http://creativecommons.org/publicdomain/zero/1.0/) applies to the data made available in this article, unless otherwise stated. 


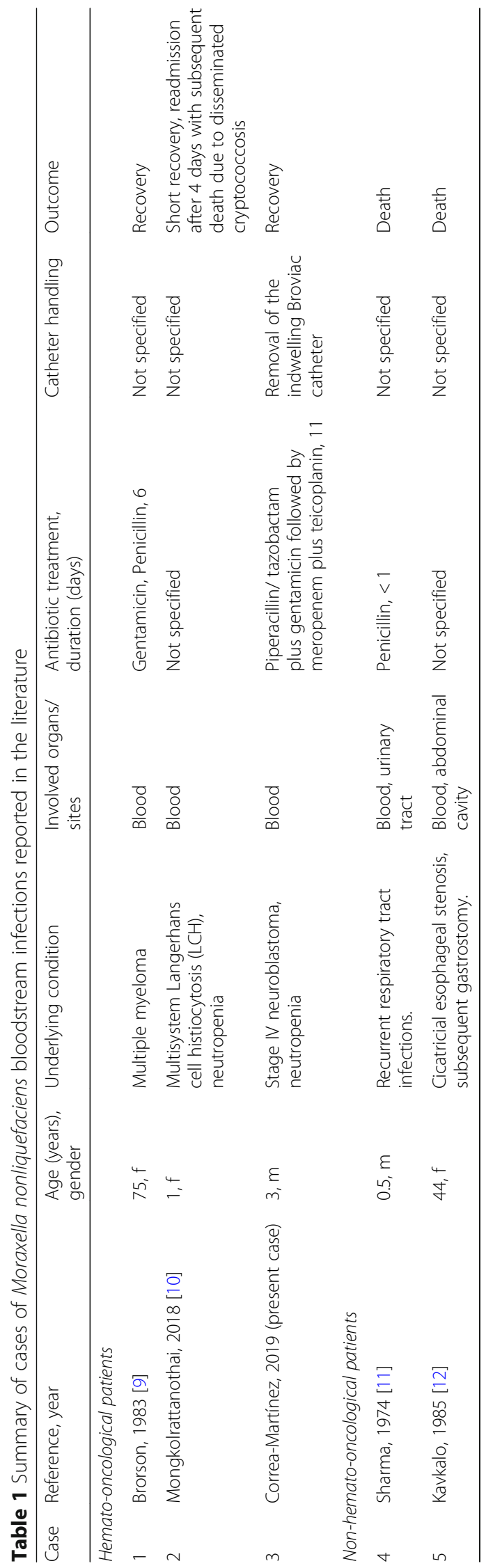


included trimethoprim/sulfamethoxazole $\left(4 \mathrm{mg} / \mathrm{m}^{2} \mathrm{BID}\right.$ on 2 days per week until day - 1), acyclovir $(5 \mathrm{mg} / \mathrm{kg}$ TID) from day -1 onward and amphotericin B (100 mg TID, oral suspension).

Five days following stem cell infusion $($ day +5$)$, the patient presented fever of up to $39.5^{\circ} \mathrm{C}$. Blood pressure, respiration and heart rate were within normal limits and physical examination was negative for an infectious focus. Laboratory parameters revealed an ANC of $<100 /$ $\mu \mathrm{L}$ and CRP of $21.1 \mathrm{mg} / \mathrm{dl}$ (normal: $<0.5 \mathrm{mg} / \mathrm{dl}$ ). Blood cultures were obtained through the indwelling triplelumen Broviac catheter, and the patient was started on empiric antibacterial therapy with piperacillin plus tazobactam (100 mg/kg TID) and gentamicin (4 mg/kg QD) per institutional standard operating procedure (Fig. 1). The next day, Gram-negative coccoid bacteria were found in the blood cultures after overnight incubation at $37^{\circ} \mathrm{C}$. Grey-white colored colonies grew aerobically on blood agar. These were identified by matrix assisted laser desorption ionization-time of flight mass spectrometry
(MALDI-TOF MS) as Moraxella nonliquefaciens. Given the lack of specific breakpoints for this microorganism, the agar diffusion test was interpreted according to the clinical breakpoints of the European Committee on Antimicrobial Susceptibility Testing for $M$. catarrhalis [14], confirming susceptibility to piperacillin/tazobactam. On day +7 , while still febrile, the patient developed low blood pressure (minimum mean arterial pressure: 51 $\mathrm{mmHg}$ ), an increased heart rate (maximum: 160 beats/minute) and decreasing oxygen saturation (minimum: $89 \%$ at room air). Physical examination revealed an ill-appearing child with prolonged capillary refill but no apparent infectious focus. Appropriate supportive measures were initiated and the indwelling Broviac central venous catheter was surgically removed for source control, resulting in prompt circulatory stabilization.

During the following days the patient had recurrent fever of up to $39.0^{\circ} \mathrm{C}$ and intermittent decreases in oxygen saturation during night time under continuous oxygen substitution. Daily follow-up blood cultures remained negative. A

\section{Stage IV Neuroblastoma High-dose chemotherapy}

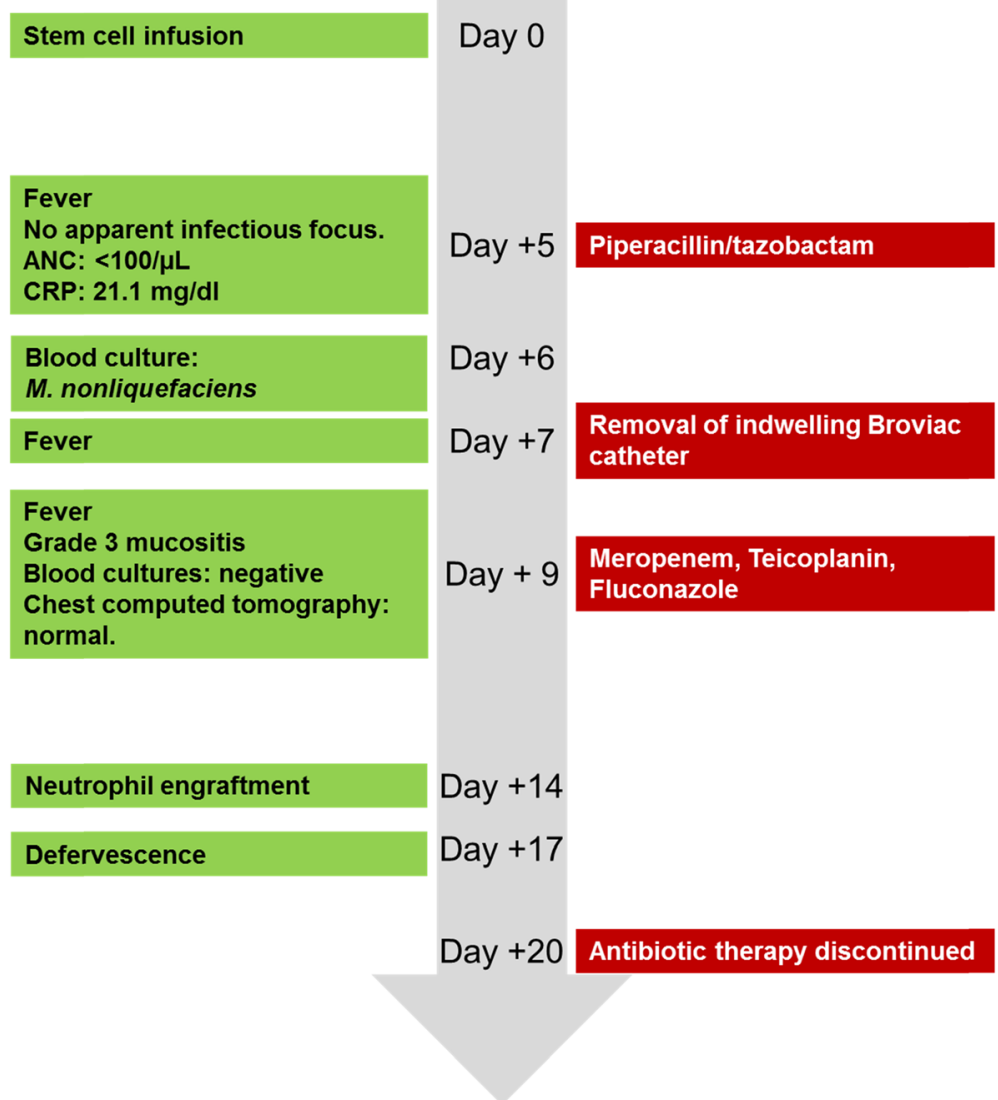

Day +22: Discharge

Fig. 1 Timeline of the patient's clinical course 
computed tomography of the chest revealed no abnormality, and clinical symptoms were attributed to grade 3 mucositis. Due to persistent fever with the possibility of a second invasive infection in the state of profound neutropenia, antibacterial therapy was escalated per institutional standard to meropenem $(20 \mathrm{mg} / \mathrm{kg}$ TID) plus teicoplanin (10 $\mathrm{mg} / \mathrm{kg}$ QD; day 1: $10 \mathrm{mg} / \mathrm{kg}$ BID), and fluconazole $(12 \mathrm{mg} /$ $\mathrm{kg}$ QD) was started to prevent mucosal and invasive candidiasis.

Following neutrophil recovery with formal neutrophil engraftment on day +14 , the patient's general condition markedly improved and definite defervescence was noted on day +17 . Antibacterial therapy with meropenem plus teicoplanin was continued for a total of 11 days of appropriate therapy, and the patient was discharged after resolution of mucositis on day +22 post stem cell infusion. Five months later the patient showed no signs of infection relapse.

\section{Discussion and conclusions}

The family Moraxellaceae is a member of the order Pseudomonadales, consists of aerobic, Gram-negative, catalase positive, nonfermenting bacteria and is subdivided into three well-recognized genera, Moraxella, Acinetobacter, and Psychrobacter [15]. The genus Moraxella includes seven species, the most common of which is Moraxella catarrhalis, a frequent cause of otitis media in children and of infectious exacerbations of chronic obstructive pulmonary disease in adults $[15,16]$.

M. nonliquefaciens is a usually non-pathogenic microorganism that exists as part of the upper respiratory tract flora [1]. It has been reported as an occasional cause of localized invasive infections, including meningitis [2], endophthalmitis [3, 4], endocarditis [5-7], pneumonia [8], and septic arthritis [17]. Immediately life-threating conditions in the form of bloodstream infections seem to be even more rare: Including the case presented here, only five cases of $M$. nonliquefaciens bacteremia have been reported in the literature to date [9-12] (Table 1). In all cases, underlying diseases may have acted as predisposing factors: three patients presented with hemato-oncological disorders and treatment-induced neutropenia, and the remaining two patients had significant comorbidities. This suggests that $M$. nonliquefaciens has a relevant pathogenicity potential in immunocrompromised and critically ill patients, while it is unlikely to cause disease in healthy hosts. Bloodstream-associated and catheter-associated infections with other Moraxella species have been reported in cancer patients in association with chemotherapyrelated mucositis [18], which constitutes a plausible portal of entry also in our patient.

The ability to produce biofilms observed in M. nonliquefaciens and other Moraxella species [15] and the interaction with other microorganisms within this milieu can contribute to bacterial persistence and resistance against antibiotic treatment [19]. In spite of the lack of specific susceptibility breakpoints for $M$. nonliquefaciens, an in vitro resistance pattern frequent in the genus Moraxella was observed, with resistance against penicillin, amoxicillin, ampicillin und piperacillin and susceptibility to piperacillin plus tazobactam that suggest the production of $\beta$-lactamases [20]. Although not possible to prove, and based on the evidence regarding the pathogenicity of $M$. nonliquefaciens in immunocompromised patients, the clinical deterioration of our patient at day two of appropriate antibacterial therapy with prompt recovery after removal of the indwelling central venous catheter suggests a role of biofilm in the pathogenesis of the evolving sepsis. This supports the importance of immediate source control for successful management of bloodstream infections by $M$. nonliquefaciens.

Although very infrequently, Moraxella nonliquefaciens may cause bloodstream infections, especially in immunocompromised patients. A successful therapeutic approach should include prompt source control and administration of adequate antibiotic therapy.

\section{Abbreviations \\ ANC: absolute neutrophil count; BID: twice a day; CRP: C-reactive protein; QD: once daily; TID: three times a day}

\section{Acknowledgements}

Not applicable.

\section{Authors' contributions}

CLCM and KKR drafted the manuscript. KKR, MF and AHG were responsible for the clinical management of the patient. MF, SK and AHG supervised the writing of the manuscript and were involved in data analysis and

interpretation. FS planned and conducted the microbiological diagnosis and contributed to the writing of the manuscript. CLCM and SK carried out additional microbiological tests. All authors read and approved the final manuscript.

\section{Funding}

Not applicable.

\section{Availability of data and materials} Not applicable.

\section{Ethics approval and consent to participate} Not applicable.

\section{Consent for publication}

Written informed consent was obtained from the patient for publication of this Case Report and any accompanying images. A copy of the written consent is available for review by the Editor of this journal.

\section{Competing interests}

The authors declare that they have no competing interests.

\section{Author details}

'Institute of Hygiene, University Hospital Münster, Robert-Koch-Strasse 41, 48149 Münster, Germany. ${ }^{2}$ Department of Pediatric Hematology and Oncology and Center for Bone Marrow Transplantation, University Children's Hospital Münster, Münster, Federal Republic of Germany. ${ }^{3}$ Institute of Medical Microbiology, University Hospital Münster, Münster, Germany. 
Received: 1 March 2019 Accepted: 20 September 2019

Published online: 11 October 2019

\section{References}

1. Yi H, Yong D, Lee K, Cho YJ, Chun J. Profiling bacterial community in upper respiratory tracts. BMC Infect Dis. 2014;14:583.

2. Kao C, Szymczak W, Munjal I. Meningitis due to Moraxella nonliquefaciens in a paediatric patient: a case report and review of the literature. JMM Case Rep. 2017:4:2.

3. Schmidt ME, Smith MA, Levy CS. Endophthalmitis caused by unusual gramnegative bacilli: three case reports and review. Clin Infect Dis. 1993;17(4):686-90.

4. Laukeland H, Bergh K, Bevanger L. Posttrabeculectomy endophthalmitis caused by Moraxella nonliquefaciens. J Clin Microbiol. 2002;40(7):2668-770.

5. Maayan H, Cohen-Poradosu R, Halperin E, Rudensky B, Schlesinger Y, Yinnon $\mathrm{AM}$, et al. Infective endocarditis due to Moraxella lacunata: report of 4 patients and review of published cases of Moraxella endocarditis. Scand J Infect Dis. 2004;36(11-12):878-81.

6. Duployez C, Loiez C, Ledoux G, Armand S, Jaillette E, Wallet F. A fatal endocarditis case due to an emerging bacterium: Moraxella nonliquefaciens. IDCases. 2017:8:12-3.

7. Rafiq I, Parthasarathy $H$, Tremlett C, Freeman $L$, Mullin M. Infective endocarditis caused by Moraxella nonliquefaciens in a percutaneous aortic valve replacement. Cardiovasc Revasc Med. 2011;12(3):184-6.

8. Rosett W, Heck DM, Hodges GR. Pneumonitis and pulmonary abscess associated with Moraxella nonliquefaciens. Chest. 1976;70(5):664-5.

9. Brorson JE, Falsen E, Nilsson-Ehle H, Rodjer S, Westin J. Septicemia due to Moraxella nonliquefaciens in a patient with multiple myeloma. Scand J Infect Dis. 1983;15(2):221-3

10. Mongkolrattanothai K, Dien BJ. Sepsis in children with febrile neutropenia. J Appl Lab Med. 2019;3(4):530-3.

11. Sharma D. Fatal septicaemia due to Moraxella nonliquefaciens. Arch Dis Child. 1974:49(12):966.

12. Kavkalo DN, Gorshevikova EV, Andreeshchev SA, Stadil'naia TE. Sepsis caused by Moraxella nonliquefaciens. Klin Khir. 1985;1:68.

13. Simon $T$, Hero B, Schulte JH, Deubzer $H$, Hundsdoerfer $P$, von Schweinitz D, et al. GPOH guidelines for diagnosis and treatment of patients with Neuroblastic tumors. Klin Padiatr. 2017:229(3):147-67.

14. EUCAST. Breakpoint tables for interpretation of MICs and zone diameters. The European Committee on Antimicrobial Susceptibility Testing. Version 8. 1. http://www.eucast.org/fileadmin/src/media/PDFs/EUCAST_files/ Breakpoint_tables/v_8.1_Breakpoint_Tables.pdf.

15. Murray PR, Baron EJ. Manual of clinical microbiology. 8th ed. Washington, D. C.: American Society for Microbiology Press; 2003.

16. Weyant RS, Moss CW, Weaver RE, Hollis DD, Jordan JG, Cook EC, et al. Identification of unusual pathogenic gram-negative aerobic and Facultatively anaerobic Bacteria. 1st ed. Baltimore, MD: Williams \& Wilkins; 1995.

17. Johnson DW, Lum G, Nimmo G, Hawley CM. Moraxella nonliquefaciens septic arthritis in a patient undergoing hemodialysis. Clin Infect Dis. 1995; 21(4):1039-40.

18. Han XY, Tarrand JJ. Moraxella osloensis blood and catheter infections during anticancer chemotherapy: clinical and microbiologic studies of 10 cases. Am J Clin Pathol. 2004;121(4):581-7.

19. Perez AC, Pang B, King LB, Tan L, Murrah KA, Reimche $J$, et al. Residence of Streptococcus pneumoniae and Moraxella catarrhalis within polymicrobial biofilm promotes antibiotic resistance and bacterial persistence in vivo. Pathog Dis. 2014;70(3):280-8.

20. Eliasson I, Kamme C, Vang M, Waley SG. Characterization of cell-bound papain-soluble beta-lactamases in BRO-1 and BRO-2 producing strains of Moraxella (Branhamella) catarrhalis and Moraxella nonliquefaciens. Eur J Clin Microbiol Infect Dis. 1992;11(4):313-21.

\section{Publisher's Note}

Springer Nature remains neutral with regard to jurisdictional claims in published maps and institutional affiliations.

Ready to submit your research? Choose BMC and benefit from:

- fast, convenient online submission

- thorough peer review by experienced researchers in your field

- rapid publication on acceptance

- support for research data, including large and complex data types

- gold Open Access which fosters wider collaboration and increased citations

- maximum visibility for your research: over $100 \mathrm{M}$ website views per year

At $\mathrm{BMC}$, research is always in progress.

Learn more biomedcentral.com/submissions 